\title{
Helen Salisbury: Disruptive innovation-technology is not the problem
}

\author{
Helen Salisbury GP
}

Oxford

Some technologies arrive gently, only gradually replacing what went before. This is what happened when motorised vehicles slowly challenged the dominance of the horse and cart. Others sweep in, and overnight the whole landscape changes. Can you remember trying to organise anything before email?

The term "disruptive innovation" was coined to describe this kind of transformative development, when a new product or service overturns existing ways of working and creates new markets.

In business there's a tension between taking time to iron out the bugs in a new product and keeping ahead of your rivals. In healthcare, where the stakes are high, we tend to proceed with caution. New drugs are tested against a placebo and existing treatments: before they're approved we must prove that they're safe and at least as good as what they replace.

GPs are being encouraged to embrace video consultations, and our health secretary has personally endorsed Babylon, a prominent commercial provider. This "disruptive innovation" may well create new markets and make money for entrepreneurs, but much of the medical community is still awaiting evidence. Will it provide safe care? Will it increase health inequalities? Will it satisfy an existing need or just create new demand?

Babylon originally stated that its online service, GP at Hand, was not suitable for patients with complex physical or mental health problems. By using enticing-but

misleading—advertising, ${ }^{1}$ Babylon has targeted young, fit, and tech savvy patients, many of whom realise only later that, in signing up, they de-register from their previous general practice. These traditional, geographically based practices then lose the capitation payments for these patients and may be pushed towards a financial cliff edge, putting the care of other patients at risk.

Will a new innovation satisfy an existing need or just create new demand?
Technology isn't the problem. GPs already spend many hours on the phone to patients, and video consulting works well in some areas of secondary care, especially when relationships are already established. ${ }^{2}$ The real innovation is not the alternatives to face-to-face consulting but the fact that Babylon has been able to use rules that were designed to increase patient choice to cherry pick healthy, low cost patients. Despite patient safety concerns and the destabilising effect on other practices, Babylon has now been given the green light to expand its services to Birmingham, in advance of an independent evaluation due to be published later this month. ${ }^{3}$ This seems a little foolhardy: would it not be sensible to wait until we're sure that the service is safe and cost effective?

Most general practices are currently running to stand still, and many are struggling even to do that. Ensuring that we can look after our elderly, complex, and unwell patients comes higher up our list of priorities than providing online consultations to the worried well. There's a risk that these elderly patients, and our traditional practices, may be left worse off in the dash to embrace all things shiny and digital.

Competing interests: See www.bmj.com/about-bmj/freelance-contributors. Provenance and peer review: Commissioned; not externally peer reviewed.

1 Advertising Standards Authority, Committee of Advertising Practice. ASA ruling on Babylon Healthcare Services Ltd t/a GP at hand. 3 Oct 2018. https://www.asa.org.uk/rulings/ babylon-healthcare-services-Itd-a18-439274.html.

2 Greenhalgh T, Shaw S, Wherton J, etal . Real-world implementation of video outpatient consultations at macro, meso, and micro levels: mixed-method study. J Med Internet Res 2018;20:e150. 10.2196/jmir.9897 29625956

3 Legraien L, Mahase E. Babylon GP at Hand given green light to expand NHS services to Birmingham. 13 Feb 2019. www.pulsetoday.co.uk/news/gp-topics/it/babylon-gp-athand-given-green-light-to-expand-nhs-services-to-birmingham/20038252.article.

Published by the BMJ Publishing Group Limited. For permission to use (where not already granted under a licence) please go to http://group.bmj.com/group/rights-licensing/ permissions 